\title{
Routes to obesity: phenotypes, food choices and activity
}

\author{
John E. Blundell* and John Cooling \\ BioPsychology Group, University of Leeds, Leeds LS2 9JT, UK
}

\begin{abstract}
Gain in body weight over a number of years could be achieved through cumulative positive energy balances. These positive balances could come about through adjustments in the various components of energy expenditure or fuel utilization, together with shifts in food selection or eating patterns leading to adjustments in macronutrient intake. This means that many combinations of intake and expenditure could lead to a positive energy balance; these combinations can be called routes to body weight gain. However, these routes are difficult to trace by studying random samples of individuals. Previous investigations have found a clear association between high fat consumption and the occurrence of obesity, and although a high fat intake is a strong behavioural risk factor for weight gain, the relationship does not constitute a biological inevitability. Some normal-weight and lean individuals appear to eat a high-fat diet. To investigate reasons for this we have studied individuals initially defined by particular clusters of dietary characteristics related to fat and carbohydrate consumption. Habitual high-fat (HF) and low-fat (LF) consumers have been termed phenotypes. Various aspects of energy expenditure (physiological and behavioural) and energy intake were measured in these individuals with contrasting profiles. HF phenotypes had high intakes of fatty foods and an overall higher energy intake than LF. However, these groups of young adult males had similar BMIs and percentage body fat. The HF had a significantly higher resting metabolic rate (RMR) and a lower RQ, together with high plasma fasting leptin levels, and a higher sleeping heart rate. In HF individuals the physical activity level was somewhat lower and they had significantly more periods of sedentary behaviour than LF subjects. Although HF individuals appear to be more vulnerable to developing obesity, both phenotypes carry particular risk factors and protective factors for weight gain. The use of phenotypes has allowed the identification of different potential routes to weight gain. Different strategies are required to prevent age-related increase in body weight in these quite different individuals.
\end{abstract}

Obesity: Phenotypes: High-fat: Low-fat

\section{Food choices, dietary intake and obesity}

There is currently a debate concerning the role played by macronutrients in the development of a positive energy balance and obesity. Most of the argument concerns dietary fat. On one hand, there is considerable evidence that highfat foods either have a disproportionally weak control over appetite, or actually stimulate appetite and lead to a positive energy balance (Lawton et al. 1993). It has been noted that 'there is evidence to indicate that the consumption of a high fat diet undermines the normal mechanisms regulating energy balance in humans' (Prentice \& Jebb 1995). In contrast, it has been stated that 'Diets high in fat do not appear to be the primary cause of the high prevalence of excess body fat in society, and reductions in fat will not be a solution' (Willett, 1998).

Some reviewers have argued that, in considering the reasons underlying a positive energy balance, low levels of physical activity are more important than a high energy intake. Some evidence even suggests that mean daily energy intake has been declining in recent years in some countries, but this is not universally true (Kuczmarski et al. 1994). Moreover, the average intake of a population may fail to indicate the behaviour of individuals in various states of energy balance or at different levels of body weight. Even with a declining mean value, some individuals could be markedly increasing their energy intake. Secondly, it is known that food intake records cannot be regarded as a reliable estimate of food actually consumed (Macdiarmid \& Blundell, 1998). For example, using the energy intake : basal metabolic rate (EI:BMR) ratio as an indicator of the acceptability of daily food diary records, it has been calculated that in one dietary survey in the UK (Gregory et al. 1990) reported energy intakes were unacceptably low in $40 \%$ of women and $30 \%$ of men. Moreover, among the obese under-reporting reached $60 \%$ in men and $70 \%$ in women (Macdiarmid et al. 1998). Since the degree of underreporting has increased over the years in some countries

\footnotetext{
*Corresponding author: J. Blundell, fax +44 113233 6670, email J.E.Blundell@ leeds.ac.uk
} 
(Fogelholm et al. 1996), probably due to people being sensitized by a dieting culture, it is often hard to accept that food intakes have genuinely fallen. Thirdly, it has now been demonstrated that a defect in a particular single gene can lead to obesity through a dramatic increase in food intake characterized as a form of hyperphagia (Montague $e t$ al. 1997; Farooqui et al. 1999). Taken together, these findings suggest that a major contributor to the frequency of obesity is a high energy intake brought about by an obesigenic environment (Egger \& Swinburne, 1997) in the face of a permissive physiological system (Blundell \& King, 1996). It should also be recognized that the effects of 'obesity' genes do not always act via metabolism but generate vulnerable behaviour or behavioural risk factors.

One characteristic of the food supply which has been identified as a likely promoter of a high energy intake and a positive energy balance is the prevalence of high-fat foods (Blundell et al. 1996; Macdiarmid et al. 1996), either of the savoury variety (Cox et al. 1999) or of the sugar-fat type (Drewnowski et al. 1992). A good deal of evidence has been assembled on this issue from both epidemiological and intervention studies. A meta-analysis has demonstrated that high-fat diets are associated with gains in body weight, and that change from a high-fat to a low-fat (highcarbohydrate) diet is associated with modest weight losses (Astrup et al. 1999).

One problem in assessing the relationship between dietary fat and obesity on the basis of large-scale surveys is the likelihood of selective under-reporting. There is evidence that fat may be selectively under-recorded (Lissner \& Heitmann, 1995), that this is particularly true for obese subjects (Goris et al. 1999), and that obese women selectively under-report sweet, high-fat foods such as cakes, pastries and biscuits (Macdiarmid et al. 1998). Interestingly, when subjects in surveys are later questioned, many voluntarily admit that they have altered their normal eating behaviour (for convenience) or deliberately not written down what has been eaten (Macdiarmid \& Blundell, 1997).

However, although the presence of high-fat foods has been identified as a major environmental 'risk factor' for weight gain, it is clear that the relationship between a highfat diet and a high BMI is not a biological inevitability (Blundell \& Macdiarmid, 1997). Some individuals who habitually consume a high-fat diet (at least at a certain age) do not appear to be gaining weight and are not obese.

This issue poses a question about the relationship between the habitual diet and the control of body weight. A further question is whether a habitually consumed diet (reflecting the operation of food choices) arises from a physiological drive for specific foods (mediated via sensory preferences or nutrient needs), or is a response to the impact of environmental forces. Is dietary choice a biological or environmental phenomenon, and what are the implications? These questions are important since the choice of a particular diet (and the consumption of nutrients) constitutes a risk factor for being in positive energy balance and subsequent weight gain.

\section{Risk factors for obesity}

Most researchers do not have any trouble accepting the idea that the state of a person's metabolism constitutes a major risk for developing weight gain and becoming obese. However, as obesity develops, metabolic characteristics change so that the state of obesity itself is associated with a different metabolic profile to that accompanying the process of weight gain. This makes it important to carry out longitudinal studies (whilst weight is increasing) as well as crosssectional studies (comparing lean and obese subjects). Recently, Ravussin \& Gautier (1999) have drawn attention to this issue and have outlined the metabolic and physiological factors associated with weight gain and with the achievement of obesity (Table 1).

The tendency to gain weight is associated with a low basal metabolic rate, low energy cost of physical activity, a low capacity for fat oxidation (relatively high RQ), high insulin sensitivity, low sympathetic nervous system activity, and a low plasma leptin concentration. In the state of obesity itself many of these risk factors (or predictors of weight gain) are reversed.

Just as certain metabolic variables (risk factors) can lead to a positive energy balance, so we can envisage certain behaviourally mediated processes which themselves constitute the risk factors leading to hyperphagia or overconsumption (high energy intake leading to a positive energy balance). These processes may be patterns of eating behaviour, the sensory or hedonic events which guide behaviour, or sensations which accompany or follow eating. For convenience, this cluster of events can be referred to as behavioural risk factors. These events may include a preference for fatty foods, weakened satiation (end of meal signals), relatively weak satiety (post-ingestive inhibition over further eating), strong oro-sensory preferences (e.g. for sweetness combined with fattiness in foods), a binge potential, and a high food-induced pleasure response. In turn, these events may be subdivided to describe more specific components leading to a risk of overconsumption.

These behavioural risk factors can be regarded as biological dispositions which create a vulnerability for weight

Table 1. Metabolic factors related to obesity itself, or to the development of obesity (after Ravussin \& Gautier, 1999)

\begin{tabular}{lcc}
\hline Metabolic factor & Associated with obesity & Predicting weight gain \\
\hline Relative metabolic rate & Normal or high & Low \\
Energy cost of physical activity & Normal & Low \\
Fat oxidation & Normal or high & Low \\
Insulin sensitivity & Low & High \\
Sympathetic nervous system activity & High & Low \\
Relative plasma leptin concentration & High & Low \\
\hline
\end{tabular}


Table 2. Postulated interactions between behavioural risk factors and the obesigenic environment which generate a tendency for over-consumption (after Blundell \& Cooling, 1999)

\begin{tabular}{|c|c|c|}
\hline $\begin{array}{l}\text { Biological vulnerability } \\
\text { (behavioural risk factor) }\end{array}$ & Environmental influence & Potential for over-consumption \\
\hline Preference for fatty foods & Abundance of high fat (high energy-dense) & $\uparrow$ fat intake \\
\hline Weak satiation (end of meal signals) & Large portion sizes & $\uparrow$ meal size \\
\hline Oro-sensory responsiveness & $\begin{array}{l}\text { Availability of highly palatable foods with } \\
\text { specific sensory-nutrient combinations }\end{array}$ & $\begin{array}{l}\uparrow \text { amount eaten } \\
\uparrow \text { frequency }\end{array}$ \\
\hline Weak post-ingestive satiety & $\begin{array}{l}\text { Easy accessibility to foods and presence } \\
\text { of potent priming stimuli }\end{array}$ & $\begin{array}{l}\uparrow \text { frequency of eating } \\
\uparrow \text { tendency to re-initiate eating }\end{array}$ \\
\hline
\end{tabular}

gain and which manifest themselves through behavioural acts, or through physiological processes which promote or permit changes in behaviour. However, such risk factors alone would be unlikely to lead to a positive energy balance in a benign environment, i.e. one in which the food supply and cultural habits worked against excessive consumption. In most societies, the food environment exploits biologically based dispositions and this promotes the achievement of a high energy intake (Table 2).

\section{The concept of behavioural phenotypes: high- and low-fat consumers}

The combination of biological dispositions (behavioural risk factors) and the presence of a conducive food environment will lead to particular patterns of consumption characterized by the size of eating episodes, the frequency of eating or the intake of particular macronutrients. Recently some attention has been given to patterns of fat intake (e.g. Baghurst et al. 1994; Macdiarmid et al. 1996), and criteria for identifying individuals as high- or low-fat consumers have been established. The level of fat consumption can be determined through a food frequency questionnaire (e.g. Margetts et al. 1989). Identification can be confirmed by using specific fat questionnaires (Roe et al. 1994) and diary recording. If these consumption patterns are robust, and may be demonstrated using other criteria or tests, then they may be termed 'phenotypes'.

In the case of high- and low-fat phenotypes, individuals are classified according to the type of diet habitually consumed. Table 3 indicates the way in which young adult male phenotypes differ according to the types of foods eaten. In

Table 3. Anthropometric, dietary ( $n=15$ per group) and metabolic characteristics ( $n=8$ per group) of male high- and low-fat phenotypes

\begin{tabular}{lcc}
\hline & \multicolumn{2}{c}{ Phenotype } \\
\cline { 2 - 3 } Parameter & High fat & Low fat \\
\hline Age (years) & 21.3 & $21 \cdot 1$ \\
BMl & $22 \cdot 1$ & $23 \cdot 1$ \\
Dietary fat intake & $132 \cdot 4$ & $83 \cdot 2^{*}$ \\
g/d & 44.8 & $29 \cdot 5^{*}$ \\
Basal metabolic rate $(\mathrm{kcal} / \mathrm{d})$ & 1,624 & $1,455^{*}$ \\
Resting RQ & 0.84 & $0.89^{*}$ \\
Plasma leptin $(\mathrm{ng} / \mathrm{ml})$ & 2.92 & $1 \cdot 79^{*}$ \\
\hline
\end{tabular}

* Significant difference between high- and low-fat phenotypes $(P<0.05$; twotail) turn, these measurable differences in the types of foods habitually selected poses the question whether the choices are biologically driven (by particular tissue needs, physiological requirements, or neurosensory characteristics) or incidentally picked up from the food environment. In either case, it will be necessary for the physiological system to adapt to the ingestion of very large amounts of specific macronutrients.

During a series of investigations of the impact of habitual high- and low-fat consumption, a group of high-fat eaters were identified who were lean despite consuming a large amount of energy and fat. These groups of high- and low-fat consumers exhibited differences in a number of nutritional and physiological variables, which prompted the idea that this clustering of variables defines a specific phenotype. Our initial investigations examined two groups of young adult males who consumed different diets associated with different amounts of fat and carbohydrate (by definition), but additionally had differing meal patterns, food choices, control of appetite and expression of hunger (Cooling \& Blundell, 1998a). In identifying the phenotypes, a dual criterion was used so that high-fat consumers ate a large absolute amount of fat and also had a high percentage fat energy. However, these phenotypes were indistinguishable from each other in physical appearance, having similar body weights, BMIs and percentage body fat. Clearly the groups were not achieving a state of energy balance in the same way. Subsequent studies found some evidence to confirm this: high-fat phenotypes (HF) had a higher basal metabolism and an increased ability to oxidize fat (lower RQ) than low-fat phenotypes (LF) (Cooling \& Blundell, 1998b) along with higher levels of fasting plasma leptin (Cooling et al. 1998).

A particular behavioural and physiological profile has been demonstrated from the study of HF and LF phenotypes. The picture poses interesting questions, as these particular cohorts of young adult male subjects displayed markedly different intakes of dietary fat and energy. Despite these large differences, subjects had almost identical body weights, BMIs and fat masses. An obvious implication is that some aspect of energy expenditure or metabolism is balancing the high-energy intake so as to maintain body weight. The observation that HF and LF differed in BMR is consistent with this idea, although the absolute size of the energy difference does not appear sufficient to preserve energy balance.

Moreover, the notion of individuals with different resting metabolic rates (RMRs) is consistent with the concept of 
'energy-sparing' and 'energy-profligate' individuals which has been used to describe two distinct groups of women (Goldberg, 1997). Interestingly, these two types are associated with different habitual intakes - the marginally nourished and the very well nourished. For years some researchers in the field of obesity research have maintained the idea that individuals exist who are capable of consuming prodigious amounts of food yet remain lean. It is therefore possible that the HF and LF phenotypes may constitute a useful investigative approach for examining the relationship between energy intake and energy utilization.

\section{Phenotypes, energy intake and expenditure}

It has been observed that individuals with contrasting habitual diets differ in some fundamental aspects of physiology and metabolism. One interpretation of the findings so far is that the habitual consumption of a high-fat diet (generating a high energy intake) leads to physiological adaptations in the form of a raised BMR. However, the converse could also be possible. This would imply that individuals with a natural (genetically conferred) high BMR select a high-energy diet. The two arguments can be formulated as an environmentally driven diet selection leading to physiological adaptations, or biologically driven energy expenditure leading to an appropriate diet selection.

In addition, it is clear that energy balance can be achieved via different combinations of forms of energy intake and types of energy expenditure. To investigate this we have measured intake and expenditure in cohorts of young male high-fat and low-fat consumers. Expenditure was measured in a number of ways. Heart rate was monitored continually for three $24 \mathrm{~h}$ periods, and the minute-by-minute measures converted to energy expended. This was achieved using the flex heart rate method, after calibrating heart rate against energy expenditure using indirect calorimetry during seven stages of activity from resting to vigorous running (Spurr et al. 1988). Physical activity energy expenditure was also assessed using the factorial method (Bouchard et al. 1983). The results indicated that LF phenotypes had somewhat higher total energy expenditure than HF, but this was not statistically significant. However both the heart rate and factorial methods indicated that LF spent more time in sedentary activities than did HF. However, the clearest difference between HF and LF was apparent in the $24 \mathrm{~h}$ profiles of heart rate which indicated that HF had markedly higher rates than LF during the $7-9 \mathrm{~h}$ of sleep (Fig. 1). During waking HF also showed three distinct peaks of heart rate which appear to correspond to meal times and may indicate the dietary induced energy expenditure (thermogenesis) associated with large meals. We have previously shown that changes in heart rate can reflect meal size (Hubert et al. 1998).

\section{Different routes to weight gain}

The comparison of HF and LF phenotypes has provided a glimpse of how energy balance (and temporary weight stability) could be achieved through mixed profiles of patterns of behaviour (eating and physical activity) and metabolism. The comparison has also indicated that distinctive patterns of food selection and eating behaviour can be associated with particular features of physical activity.

For these groups of young adult males who are currently maintaining a normal BMI, their apparent weight stability appears to be achieved through different combinations of behavioural and physiological factors. Each group can be said to possess risk factors and protective factors. For example, HF phenotypes have (by definition) a markedly higher intake of fatty foods and a higher overall energy intake. The cost of digesting and assimilating the fat is lower than for protein or carbohydrate. A further risk factor for the $\mathrm{HF}$ is their overall lower physical activity energy expenditure, characterized by significantly greater periods of sedentariness. However, these risk factors appear to be compensated for by a relatively higher RMR, a lower RQ and a much higher night-time metabolism (reflected in a higher sleeping heart rate). It is possible that some of these metabolic variables are mediated by the measured higher plasma leptin values (Cooling et al. 1998).

In contrast, LF phenotypes are protected by their low-fat (low-energy) diet and by a relatively higher level of physical

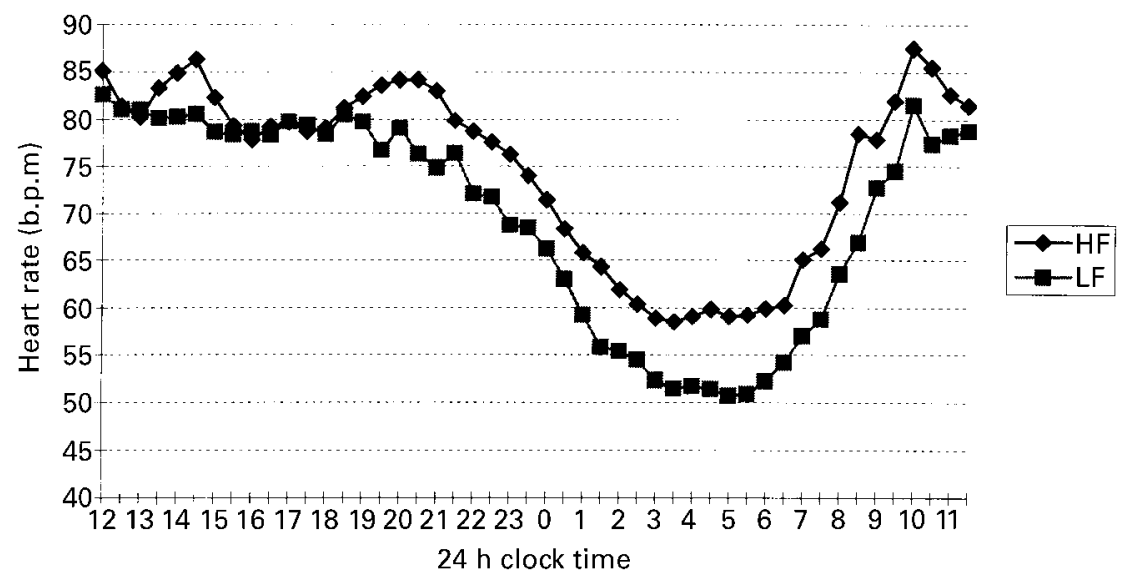

Fig. 1. $24 \mathrm{~h}$ profile of heart rate in high-fat (HF) and low-fat (LF) phenotypes. Average heart rate was completed for every $30 \mathrm{~min}$ period. Time point 1 corresponds to 12 noon. 
Table 4. Conceptualization of physiological and behavioural risk factors contributing to current weight stability in young adult male habitual consumers of high-fat or low-fat diets

\begin{tabular}{|c|c|c|c|c|}
\hline \multirow[b]{2}{*}{ Phenotype* } & \multicolumn{2}{|c|}{ Current situation } & \multicolumn{2}{|c|}{ Future situation } \\
\hline & Risk factors & Protection factors & Danger of weight gain & $\begin{array}{c}\text { To prevent age-related } \\
\text { weight gain }\end{array}$ \\
\hline High fat & $\begin{array}{l}\text { High-fat diet } \\
\text { Large total energy intake } \\
\text { High sedentariness }\end{array}$ & $\begin{array}{l}\text { Relatively high RMR } \\
\text { High night-time energy } \\
\text { expenditure } \\
\text { Low RQ }\end{array}$ & $\begin{array}{l}\text { Further increase in sedentariness } \\
\text { Maintenance of high-fat diet }\end{array}$ & $\begin{array}{l}\text { Increase physical activity } \\
\text { Slowly reduce fat in diet }\end{array}$ \\
\hline Low fat & $\begin{array}{l}\text { Relatively low RMR } \\
\text { High RQ }\end{array}$ & $\begin{array}{l}\text { Low-fat (low-energy) diet } \\
\text { Lower total daily energy intake } \\
\text { Low level of sedentariness }\end{array}$ & $\begin{array}{l}\text { Introduction of high-fat foods or } \\
\text { occasional high-fat eating } \\
\text { episodes } \\
\text { Increasing sedentariness }\end{array}$ & $\begin{array}{l}\text { Maintain high level of } \\
\text { physical activity } \\
\text { Maintain low-fat diet }\end{array}$ \\
\hline
\end{tabular}

\footnotetext{
* These phenotypes are vulnerable to weight gain from different factors.
}

activity-induced energy expenditure, characterized by a smaller amount of time spent in sedentary behaviours. This could mean that LF phenotypes display higher levels of non-exercise activity thermogenesis (Levine et al. 1999). It remains to be demonstrated whether HF or LF would respond more sharply to large supplementary energy loads.

It is paradoxical that LF phenotypes who display judicious forms of food choices and physical activity apparently possess metabolic risk factors such as relatively low RMR, high RQ and high insulin sensitivity, which are regarded as predictors of weight gain. This mixed profile of high metabolic risk but strong behavioural protection means that habitual consumers of low-fat diets are likely to resist weight gain as long as their behaviour does not change. However, in the short term LF phenotypes could be vulnerable to the effects of occasional high-fat eating episodes which are known to occur even in consumers of low-fat foods (e.g. Blundell \& Macdiarmid, 1997) and which do not normally induce a corresponding level of fat oxidation. Indeed, it takes 3-5 d of high-fat feeding before a significant rise in fat oxidation occurs (Schrauen et al. 1997). Postobese subjects also display low levels of fat oxidation (Astrup et al. 1997), which is possibly due in part to recently acquired low-fat dietary habits.

The identification and comparison of two groups of individuals with contrasting habitual dietary habits has indicated how different combinations of behavioural and physiological profiles can produce apparent energy balance (at least in the short term) and weight stability.

On the basis of the descriptions of these phenotypes it can be deduced that there exist various routes to weight gain according to the particular combinations of physiological and behavioural variables present, and the extent to which these change over time. This is important, as it is often overlooked that age is the best predictor of BMI, and that the prevalence of obesity and average BMI increases with age over a very large portion of the life span. This conceptualization is set out in Table 4.

A review of the literature (epidemiological and experimental) indicates that the total amount of fat consumed stands as the single most potent food-related risk factor for weight gain. However, some experts have nominated saturated fat rather than total fat or high energy density rather than fat per se, or foods generating a high glycaemic index. It is clear that in the domain of nutrition and body-weight regulation we are not dealing with a 'biological inevitability'; people can achieve a positive energy balance on a range of diets which stimulate energy intake to overtake energy expenditure.

The identification of specific phenotypes has exposed and contrasted clear differences in physiological and behavioural variables. Table 4 indicates the way in which different factors could lead to weight gain or protect against age-related weight increases. Since it is known that physiological variables such as RMR and fat oxidation (Melanson et al. 1997) decline with age, specific behavioural change must occur in order to compensate for these age-related risk factors.

The concept of different routes to obesity through a variety of nutritional scenarios can be integrated with the notion of individuals varying in susceptibility to different dietary inputs. Whether by genetic determination, physiological adaptation or nutrient-gene interactions, some individuals will be better equipped physiologically to deal with a high-fat, high-energy diet. Although we maintain that a diet replete with fatty foods remains the single most prominent food-related risk factor, it is clear that some individuals can remain lean on such a diet - at least for a certain period of time.

This approach gives an equal weighting to food choice and appetite control, physical activity (deliberate and incidental), and physiological factors, in the maintenance of energy balance and in departures from balance. It follows that there will be different combinations of these variables (risk factors) which allow individuals to maintain energy balance, and which permit the attainment of a positive energy balance. Some individuals will be vulnerable because of genetically based risk factors, others because of the potency of environmentally based factors. It will thus be easier to achieve control over certain risk factors than over others. The combination of different routes to obesity puts the emphasis on individual patterns (of physiology and behaviour) and seems more realistic than the idea of a single regulator of body weight.

\section{References}

Astrup A, Raben A, Buemann B \& Toubro S (1997) Fat metabolism in the predisposition to obesity. Annals of the New York Academy of Sciences 827, 417-430. 
Astrup A, Ryan L, Storgaard M, Saris WHM \& Hill JO (1999) Does dietary fat affect obesity? A meta-analysis of ad libitum low-fat diets. British Journal of Nutrition, in press.

Baghurst KI, Baghurst PA \& Record SJ (1994) Demographic and dietary profiles of high and low fat consumers in Australia. Journal of Epidemiology and Community Health 48, 26-32.

Blundell JE \& Cooling J (1999) High-fat and low-fat (behavioural) phenotypes: biology or environment. Proceedings of the Nutrition Society 58, 1-5.

Blundell JE \& King NA (1996) Overconsumption as a cause of weight gain: behavioural-physiological interactions in the control of food intake (appetite). In The Origins and Consequences of Obesity (Ciba Foundation Symposium 201), pp. 138-158. Chichester, UK: Wiley.

Blundell JE \& Macdiarmid JI (1997) Passive overconsumption fat intake and short-term energy balance. Annals of the New York Academy of Sciences 827, 392-407.

Blundell JE, Lawton CL, Cotton JR \& Macdiarmid JI (1996) Control of human appetite: implications for the intake of dietary fat. Annual Review of Nutrition 16, 285-319.

Bouchard C, Tremblay A, Leblanc C, Lortie G, Savard R \& Theriault G (1983) A method to assess energy expenditure in children and adults. American Journal of Clinical Nutrition 37, 461-467.

Cooling J \& Blundell JE (1998a) Are high-fat and low-fat consumers distinct phenotypes? Differences in the subjective and behavioural response to energy and nutrient challenges. European Journal of Clinical Nutrition 52, 193-201.

Cooling J \& Blundell JE (1998b) Differences in energy expenditure and substrate oxidation between habitual high fat and low fat consumers (phenotypes). International Journal of Obesity 22, 612-618.

Cooling J, Barth J \& Blundell JE (1998) The high-fat phenotype: is leptin involved in the adaptive response to a high fat (high energy) diet? International Journal of Obesity 22, 1132-1135.

Cox DN, Perry L, Moore PB, Vallis L \& Mela DJ (1999) Sensory and hedonic associations with macronutrient and energy intakes of lean and obese consumers. International Journal of Obesity 23, 403-410.

Drewnowski A, Kurth C, Holden-Wiltse J \& Saari J (1992) Food preferences in human obesity: carbohydrates versus fats. Appetite 18, 207-221.

Egger G \& Swinburn B (1997) An 'ecological' approach to the obesity pandemic. British Medical Journal 315, 477-480.

Farooqi IS, Jebb SA, Landmack G, Lawrence E, Cheetham CH, Prentice AM, Hughes IA, McCamish MA \& O'Rahilly S (1999). Recombinant leptin induces weight loss in human congenital leptin deficiency. New England Journal of Medicine 341, 879-884.

Fogelholm M, Mannisto S, Vartiainen E \& Pietinen P (1996) Determinants of energy balance and overweight in Finland 1982 and 1992. International Journal of Obesity 20, 1097-1104.

Goldberg GR (1997). From individual variation in energy intakes to variations in energy requirements and adaptations to them. British Journal of Nutrition 78, S81-S94.

Goris AHC, Westerterp-Platenga MS \& Westerterp KR (1999) Under-eating and under-recording of habitual food intake in obese men; selective under-reporting of fat intake. American Journal of Clinical Nutrition 69, in press.

Gregory J, Foster K, Tyler H \& Wiseman M (1990) The Dietary and Nutritional Survey of British Adults. London, UK: HMSO (The Stationery Office).
Hubert P, King NA \& Blundell JE (1998) Uncoupling the effects of energy expenditure and energy intake: appetite response to short-term energy deficit induced by meal omission and physical activity. Appetite 31, 9-19.

Kuczmarski RJ, Flegal KM, Campbell SM \& Johnson CL (1994) Increasing prevalence of overweight among US adults. The National Health and Nutrition Surveys, 1960-1991. JAMA 272, 205-211.

Lawton CL, Burley VJ, Wales JK \& Blundell JE (1993) Dietary fat and appetite control in obese subjects: weak effects on satiation and satiety. International Journal of Obesity 17, 409-416.

Levine JA, Eberhardt NL \& Jensen MD (1999) Role of nonexercise activity thermogenesis in resistance to fat gain in humans. Science 283, 212-214.

Lissner L \& Heitmann BL (1995) Dietary fat and obesity: evidence from epidemiology. European Journal of Clinical Nutrition 49, 79-90.

Macdiarmid JI \& Blundell JE (1997) Dietary under-reporting: what people say about recording their food intake. European Journal of Clinical Nutrition 51, 199-200.

Macdiarmid JI \& Blundell JE (1998) Assessing dietary intake: who, what and why of under-reporting. Nutrition Research Reviews 11, 1-24.

Macdiarmid JI, Cade JE \& Blundell JE (1996) High and low fat consumers, their macronutrient intake and body mass index: further analysis of the National Diet and Nutrition Survey of British Adults. European Journal of Clinical Nutrition 50, 505512.

Macdiarmid JI, Cade JE \& Blundell JE (1998) The sugar-fat relationship revisited: differences in consumption between men and women of varying BMI. International Journal of Obesity 22, 1053-1061.

Margetts BM, Cade JE \& Osmond C (1989) Comparison of a food frequency questionnaire with a diet record. International Journal of Epidemiology 18, 868-873.

Melanson KJ, Saltzman E, Russell RR \& Roberts S (1997) Fat oxidation in response to four graded energy challenges in younger and older woman. American Journal of Clinical Nutrition 66, 860-866.

Montague CT, Farooqi IS, Whitehead JP, Soos MA, Rau H, Wareham NJ, Sewter CP, Digby JE, Mohammed SN, Hurst JA, Cheetham CH, Earley AR, Barnett AH, Prins JB \& O'Rahilly S (1997) Congenital leptin deficiency is associated with severe early-onset obesity in humans. Nature 387, 903908.

Prentice AM \& Jebb SA (1995) Obesity in Britain: gluttony or sloth? British Medical Journal 311, 437-439.

Ravussin E \& Gautier J-F (1999) Metabolic predictors of weight gain. International Journal of Obesity 23, 37-41.

Roe L, Strong C, Whiteside C, Neil A \& Mant D (1994) Dietary intervention in primary care: validity of the DINE method for diet assessment. Family Practice 11, 375-378.

Schrauen P, van Marken Lichtenbelt WD, Sarin WMH \& Westerterp KR (1997) Changes in fat oxidation in response to a high fat diet. American Journal of Clinical Nutrition 66, 276-282.

Spurr GB, Prentice AM, Murgatroyd PR, Goldberg GR, Reina JC \& Christman NT (1988) Energy expenditure from minute-byminute heart rate recording: comparison with indirect calorimetry. American Journal of Clinical Nutrition 48, 552-559.

Willett WC (1998) Is dietary fat a major determinant of body fat? American Journal of Clinical Nutrition 67 (Suppl. 3), 556S$562 \mathrm{~S}$. 